\title{
Metastasis-associated gene 1 promotes invasion and migration potential of laryngeal squamous cell carcinoma cells
}

\author{
HAILI ZHANG $^{1,2}$, DONG YANG ${ }^{2}$, HAIJUAN WANG ${ }^{2}$, SHUXIN WEN $^{1}$, JIAN LIU $^{2}$, \\ QINGCHUN LUAN ${ }^{2}$, YIXUAN HUANG ${ }^{2}$, BINQUAN WANG $^{1}$, CHEN LIN $^{2}$ and HAILI QIAN ${ }^{2}$ \\ ${ }^{1}$ Department of Otolaryngology Head and Neck Surgery, The First Hospital, Shanxi Medical University, \\ Taiyuan, Shanxi 030001; ${ }^{2}$ State Key Laboratory of Molecular Oncology, Cancer Institute/Cancer Hospital, \\ Chinese Academy of Medical Sciences and Peking Union Medical College, Chao Yang, Beijing 100021, P.R. China
}

Received April 28,2013; Accepted November 1, 2013

DOI: $10.3892 / 01.2013 .1729$

\begin{abstract}
Overexpression of the metastasis-associated gene 1 (MTAl) has previously been found to be associated with progression of various cancer types to the metastasis stage. The function of MTAl in laryngeal squamous cell carcinoma (LSCC) remains unclear. To explore the significance of MTAl in the invasion and migration processes in LSCC, gene transfection and RNA interference (RNAi) were performed to study the biological function of MTA1 in the LSCC cell line, HEP-2. Results showed that MTA1 promoted the invasion, adhesion and migration behavior of LSCC cells. RNAi against MTAl significantly decreased the malignant phenotypes of cancer cells. MTAl may be important in the process of LSCC invasion and metastasis.
\end{abstract}

\section{Introduction}

Laryngeal squamous cell carcinoma (LSCC) represents the second most common malignant neoplasm of the respiratory tract after lung cancer (1). LSCC has a strong propensity to metastasize to regional lymph nodes, which decreases the cure and survival rates $(2,3)$. Multiple steps and factors are involved in the process of malignant cancer progression $(4,5)$. This process is under the control of many metastasis-associated genes. Among these, metastasis-associated gene 1 (MTAl) is positively correlated with cancer metastasis in many cancer types. Toh et al (6) first cloned MTAl from the highly metastatic mammary adenocarcinoma cell line by differential

Correspondence to: Professor Chen Lin or Professor Haili Qian, Cancer Institute/Cancer Hospital, Chinese Academy of Medical Sciences and Peking Union Medical College, State Key Laboratory of Molecular Oncology, 17 Panjiayuan Nanli, Chao Yang, Beijing 100021, P.R. China

E-mail: clinwk@yahoo.com.cn

E-mail: qianhaili001@163.com

Key words: metastasis-associated gene 1, laryngeal squamous cell carcinoma, invasion, metastasis
cDNA library screening. MTA1 is a subunit of the nucleosome remodeling and deacetylase (NURD) complex, which is involved in chromatin remodeling and histone deacetylation in gene expression regulation (7). MTAl functions as a transcriptional coregulator, regulating the downstream target genes that encode effector proteins controlling cancerous processes (8). MTA1 overexpression is positively correlated with in vitro migration and invasion ability in KYSE150 and B16F10 melanoma cell lines, and inhibition of MTA1 protein expression results in growth inhibition of cancer cell lines $(9,10)$. Sasaki et al $(11,12)$ reported that MTAl mRNA was overexpressed in thymoma and advanced lung cancer. It has also been reported that MTAl may be involved in initiating carcinogenesis $(13,14)$. Miyatani et al $(15)$ compared the expression of MTA1 in normal esophageal epithelium, normal gastric epithelium and gastro-esophageal junction cancer, and found that MTA1 levels were significantly higher in cancer samples than in their normal counterparts. Moreover, in tonsil cancer, MTAl is positively correlated with lymphatic metastasis (16). It has also been indicated that MTA1 is correlated with tumor angiogenesis and poor outcome in patients with early-stage non-small cell lung cancer (NSCLC) (17). This line of evidence indicates that MTA1 may become a new marker for predicting cancer metastasis, or even cancer outcome.

Concerning the molecular mechanism of MTAl in cancer cell metastasis, MTAl has been reported to be involved in cancer development in several ways. MTA1-interacting coactivator has been identified as a molecule that interacts with MTA 1 to regulate estrogen receptor- $\alpha$ transactivation (18). Yoo et al (19) reported that MTAl stabilizes hypoxia-inducible factor- $1 \alpha$ protein by recruiting histone deacetylase 1 , and is correlated with angiogenesis in cancer development (20). Since MTAl is a histone deacetylase (HDAC)-interacting protein that modulates the epigenetic status of its target genes, it is expected to widely influence the expression pattern of the cancer-related gene spectrum. Ghanta et al (21) revealed, using a profiling assay, that MTAl regulation was partially under the control of p53. When p53 is functional, MTA1 mainly focuses on inflammatory and antimicrobial responses; when p53 is absent, MTAl predominantly targets genes in cancer signaling. MTAl is correlated with cigarette smoking in NSCLC, indicating its importance in the smoking-related progression 
of this type of cancer (22). MTAl has also been reported to regulate the anoikis of human prostate cancer cells (23), which reveals a new subfield of MTA1 mechanisms.

MTA1 is a corepressor responsible for estrogen receptor repression at the transcriptional level (24). A naturally occurring MTAl variant, MTAls, can sequester estrogen receptor- $\alpha$ in the cytoplasm (25). Estrogen receptor involvement is the first insight into the p53-independent function of MTA1 in the DNA damage response involving the p21/WAF1-proliferating cell nuclear antigen pathway (26). MTA1 is required for the ATR-mediated DNA damage checkpoint function (27). UV radiation stabilizes $M T A 1$ and increases MTAl binding to ATR. Other molecules found to be associated with MTA1 expression include RECK (28), HDAC1 (15) and MMP-9 (29). Silencing MTAl by RNA interference (RNAi) reverses the malignant phenotypes, including adhesion, migration and invasiveness of cervical cancer cells ( $\mathrm{SiHa}$ ) via altered expression of p53 and the E-cadherin/ $\beta$-catenin complex (30).

No systematic biological studies have been performed on LSCC to date. This study aimed to determine the biological role of MTA1 in LSCC using gain-of-function and RNAi techniques.

\section{Materials and methods}

Cell lines. The human LSCC cell line HEP-2 and the human keratinocyte HaCaT cell line (State Key Laboratory of Molecular Oncology, Beijing, China) were cultured in RPMI-1640 and DMEM medium (Gibco-BRL, Grand Island, NY, USA), respectively, supplemented with $10 \%$ (v/v) fetal calf serum (FCS) (Hyclone Laboratories, Inc., Logan, UT, USA), $2 \mathrm{mM}$ L-glutamine and antibiotics (penicillin-streptomycin at $100 \mathrm{U} / \mathrm{ml}$ ) in a humidified atmosphere of $5 \% \mathrm{CO}_{2}$ at $37^{\circ} \mathrm{C}$. The keratinocyte $\mathrm{HaCaT}$ cell line is an immortalized normal epithelial cell line.

Reagents. Lipofectamine 2000 was purchased from Invitrogen Life Technologies (Carlsbad, CA, USA). siRNA sequence was chemically synthesized by Jikai Co. (Shanghai, China). The MTA1 primary antibody was from Santa Cruz Biotechnology, Inc. (sc-9446; Santa Cruz, CA, USA) and the horseradish peroxidase-conjugated secondary antibody was from Zhongshan Biotech, Co., Ltd (Zhongshan, China). The ECL detection system was purchased from Amersham Biosciences (Piscataway, NJ, USA). The Boyden chamber system and polycarbonate membrane ( $8 \mu \mathrm{m}$ pore size) were obtained from Neuro Probe, Inc. (Canada). Matrigel was purchased from BD Biosciences (San José, CA, USA).

siRNA and plasmid transfection. The 21-nt siRNA sequence was chemically synthesized (Jikai Co.). The target sequences of the siRNA for the MTAl gene (MTAl-siRNA) were as follows: Sense, 5'-GAACAUCU ACGACAUCUCCdTdT-3' and antisense, 5'-GGAGAU GUCGUAGAUGUUCdTdT-3' (9). The MTAl-siRNA was dissolved in sterilized and RNase-free water and annealed. The final concentration was $20 \mu \mathrm{M}$. Lipofectamine 2000 (20 $\mu \mathrm{l} / \mathrm{ml}$, Invitrogen Life Technologies) was used to transfect the HEP-2 cell line according to the manufacturer's instructions. A sequence non-specific to any known gene was used as a negative control (Jikai Co.).
The pcDNA3-MTA1 plasmid was provided by Dr Mahoney (Jefferson Institute of Molecular Medicine, Thomas Jefferson University, Philadelphia, PA, USA), and the transfection was performed according to the manufacturer's instructions. The cells transfected with pcDNA3-MTAl were selected by G418 prior to use.

Western blotting analysis. Cells were grown to $80 \%$ confluence and rinsed twice with 1X PBS prior to harvesting. Total cell protein was extracted using PBS buffer containing aprotinin $(2 \mu \mathrm{g} / \mathrm{ml})$, PMSF $(100 \mu \mathrm{g} / \mathrm{ml})$, leupeptin $(2 \mu \mathrm{g} / \mathrm{ml})$ and $1 \%$ Nonidet P-40. Protein concentration was determined using the Gene Quant Pro-91738 protein assay system (Bio-Rad Laboratories, Inc, Hercules, CA, USA). Samples were briefly electrophoresed in $10 \%$ SDS-PAGE and transferred to nitrocellulose membranes using a semidry transfer system. Nonspecific binding was blocked for $2 \mathrm{~h}$ in $5 \%$ fat-free milk in PBS buffer, pH 7.6. Blots were first incubated with MTAl primary antibody (1:200) (Santa Cruz Biotechnology, Inc.) for $2 \mathrm{~h}$ at $37^{\circ} \mathrm{C}$, and then with corresponding horseradish peroxidase-conjugated secondary antibody (1:2,000, Zhongshan Biotech) for $1 \mathrm{~h}$ at room temperature. Signals were visualized using the ECL detection system according to the manufacturer's instructions (Amersham Biosciences). The detection was repeated three times.

Migration and invasion assay. Migration assays were performed using a Boyden chamber system (Neuro Probe, Inc., Gaithersburg, MD USA) with a fibronectin-precoated $(0.5 \mathrm{mg} / \mathrm{ml})$ polycarbonate membrane $(8 \mu \mathrm{m}$ pore size $)$ (AP48; Neuro Probe, Inc.) as described previously, with minor modifications (9). The invasion chamber was identical to the migration chamber, but with the $250 \mu \mathrm{g} / \mathrm{ml}$ Matrigel (BD Biosciences) precoated polycarbonate membrane. For both assays, the bottom chambers were filled with medium containing 10\% FCS, RPMI-1640 and 2\% BSA as chemoattractant, and medium containing serum-free RPMI-1640, and $0.2 \%$ BSA was added into the top chambers. Treated or control cells $\left(2 \times 10^{4}\right.$ per well) were added to the top chambers, followed by a 10 -h incubation at $37^{\circ} \mathrm{C}$ and $5 \% \mathrm{CO}_{2}$. Three independent experiments were performed for each set. The cells migrated through and adhered to the bottom of the membrane were then fixed and stained with Giemsa dye. The cells that migrated to the lower side of the membrane were mounted under a microscope and averaged. This experiment was repeated three times.

Adhesion assay. Adhesion assay was performed by the MTT assay. The same numbers of MTA1-siRNA-, control-siRNAand pcDNA3-MTA1-transfected HEP-2 cells $\left(1 \times 10^{5}\right)$ were plated into the Matrigel-precoated (50 $\mu \mathrm{g} / \mathrm{ml})$ 96-well plate in triplicate. The groups of cells were washed for 30, 60 and $90 \mathrm{~min}$, respectively, to remove the non-adherent cells. After washing, the adherent cells were measured with MTT assay at $490 \mathrm{~nm}$ wavelength. The OD values reflect the proportion of cells that adhered to the Matrigel-coated 96-well plate. This experiment was repeated in triplicate.

Wound healing assay. To perform the wound healing assay, pcDNA3-MTA1-, MTA1-siRNA- and control-siRNA-trans- 
fected HEP-2 cells were implanted into the Matrigel (50 $\mu \mathrm{g} / \mathrm{ml})$-coated 35-mm culture dishes, as described by Qian et al (9). When the cells grew to $80 \%$ confluence, a sterilized tip was used to draw a line with the same width on the bottom of the dishes. Images were captured at 8, 16 and $24 \mathrm{~h}$ after the wounding. Data shown in the text are representative of three independent repeats.

RT-PCR analysis. Total RNA was isolated from HEP-2 and HaCaT cells, and RT-PCR was performed according to the manufacturer's instructions to detect gene expression (K0011 RT-PCR kit, Vigorous Biotechnology, Beijing, China). The primers used for amplification were as follows: MTAl (forward primer: 5'-CCGGGCCTGCGAGAGCTGTTACAC-3', reverse primer: 5'-CACGGCTTCCAGCGGCTTGCGTAC-3'); $\beta$-actin (forward primer: 5'-ACCACAGTCCATGCCATCAC-3', reverse primer: 5'-TCCACCACCCTGTTGCTGTA-3'). The cycling conditions were as follows: Initial denaturation at $94^{\circ} \mathrm{C}$ for $5 \mathrm{~min}$, followed by 28 cycles at $94^{\circ} \mathrm{C}$ for $30 \mathrm{sec}, 55^{\circ} \mathrm{C}$ for $40 \mathrm{sec}$ and $72^{\circ} \mathrm{C}$ for $30 \mathrm{sec}$.

Statistical analyses. The data were analyzed by ANOVA. The statistical analysis was performed using SPSS 11.0 software (SPSS, Inc, Chicago, IL, USA), and $\mathrm{P}<0.05$ was considered to indicate a statistically significant difference.

\section{Results}

MTA1 mRNA expression in HEP-2 and HaCaT cell lines. Expression of MTA1 mRNA in Hep-2 and HaCaT cell lines was evaluated by RT-PCR. The level of MTA1 mRNA was significantly higher in the LSCC cell line, HEP-2, than in the immortalized keratinocyte $\mathrm{HaCaT}$ cell line (Fig. 1). This result indicates that LSCC cells have higher levels of MTAl expression than normal cell lines, as indicated by the active role of MTAI in LSCC. Thus, for further experiments in this study, the HEP-2 cell line was selected to study MTAl biological functions.

Confirmation of MTA1 expression by RT-PCR and western blot analysis in the gain-of-function and loss-of-function studies. We performed gene transfection and RNA interference to study MTA1 functions. RT-PCR and western blot analysis confirmed the changes in MTAl levels after pcDNA3-MTAI and pSilencer3.1-MTAl-siRNA transfection. We found that the expression of MTAl was either suppressed or increased at the mRNA and protein level after treatment. The mRNA levels corresponding to pcDNA3-MTA1, control-siRNA and MTA1-siRNA, presented by density value, were $2.78 \pm 0.046$, $1.04 \pm 0.119$ and $0.32 \pm 0.046$, respectively. The protein levels were $2.69 \pm 0.267,1.07 \pm 0.112$ and $0.36 \pm 0.069$, respectively. Compared with the control-siRNA-transfected cells, MTAl-siRNA significantly decreased the expression of MTAI $(\mathrm{P}<0.05)$, while pcDNA3-MTA1 significantly enhanced MTA1 expression $(\mathrm{P}<0.05)$ (Figs. 2 and 3$)$.

In vitro migration and invasion ability of $\mathrm{HEP}-2$ cells following transfection of pcDNA3-MTA1 and pSilencer3.1-MTA1-siRNA. The in vitro migration and invasion ability of HEP-2 cells transfected with pcDNA3-MTA1 and MTA 1 -siRNA were studied using the Boyden chamber

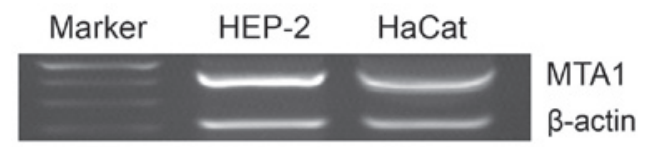

Figure 1. MTA1 expression in HEP-2 and HaCaT cell lines. Total RNA was extracted from the cultured cell lines and reversely transcribed to cDNA as a template for RT-PCR amplification. The level of MTA1 mRNA in the HEP-2 cell line was significantly higher than that in the HaCaT cell line. MTA1, metastasis-associated gene 1 .

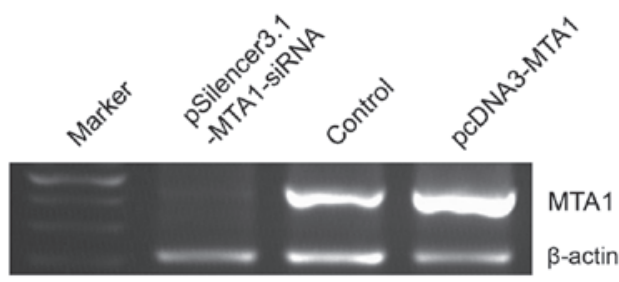

Figure 2. RT-PCR determined the effects of pcDNA3-MTA1, control-siRNA and MTA1-siRNA transfection on MTA1 expression at the mRNA level. pcDNA3-MTA1 and MTA1-siRNA were transfected into the cell line with Lipofectamine 2000. Total RNA was extracted and RT-PCR was performed. pcDNA3-MTA1 transfection increased MTA1 mRNA levels, while MTA1-siRNA decreased MTA1 mRNA levels. MTA1, metastasis-associated gene 1 .

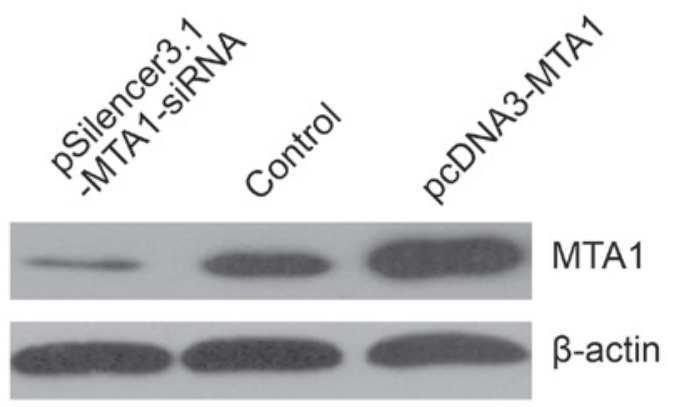

Figure 3. Western blot analysis of $M T A 1$ expression after transfection with pcDNA3-MTA1 and pSilencer3.1-MTA1-siRNA. pcDNA3-MTA1 and MTA1-siRNA were transfected into the cell line with Lipofectamine 2000. Whole protein was extracted and loaded for SDS-PAGE separation. The protein was transferred to a nitrocellulose membrane and pcDNA3-MTA1 increased MTA1 expression and MTA1-siRNA greatly decreased MTAI levels. MTA1, metastasis-associated gene 1.

model as described in Materials and methods. In the migration assay, responding to pcDNA3-MTA1, control-siRNA and MTA 1 -siRNA, the number of cells that migrated to the lower side of the membrane was $549.2 \pm 21.51,352 \pm 25.03$ and $120.8 \pm 17.28$, respectively. The number of cells that migrated to the lower side of the membrane in the invasion assay was $423.6 \pm 14.15,301.2 \pm 25.4$ and $115.4 \pm 15.52$, respectively. Compared with the control-siRNA-transfected cells, MTA1-siRNA significantly decreased the migration and invasion ability of HEP-2 cells $(\mathrm{P}<0.05)$, while pcDNA3-MTA1 significantly enhanced the migration and invasion ability of HEP-2 cells $(\mathrm{P}<0.05)$ (Figs. 4 and 5).

Adhesion assay of pcDNA3-MTA1- and MTA1-siRNA-treated $H E P-2$ cell line. The adhesion of cancer cells to the extracellular matrix and cell surface molecules is a key step during metas- 


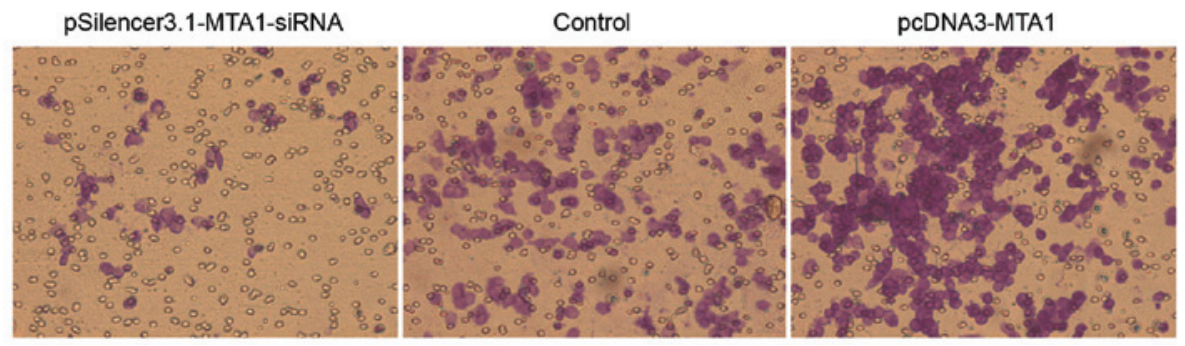

Figure 4. Migration ability of HEP-2 cells after MTA1 overexpression and RNAi. Cells treated by MTA1 overexpression and MTA1 silencing were loaded into the upper wells of the chamber. Cells moved to the lower side of the fibronectin-precoated polycarbonate membrane were counted and analyzed. Compared with the control, pcDNA3-MTAl transfection promoted cell migration $(\mathrm{P}<0.05)$, while MTAl-siRNA transfection suppressed cell migration $(\mathrm{P}<0.05)$. MTA1, metastasis-associated gene 1.

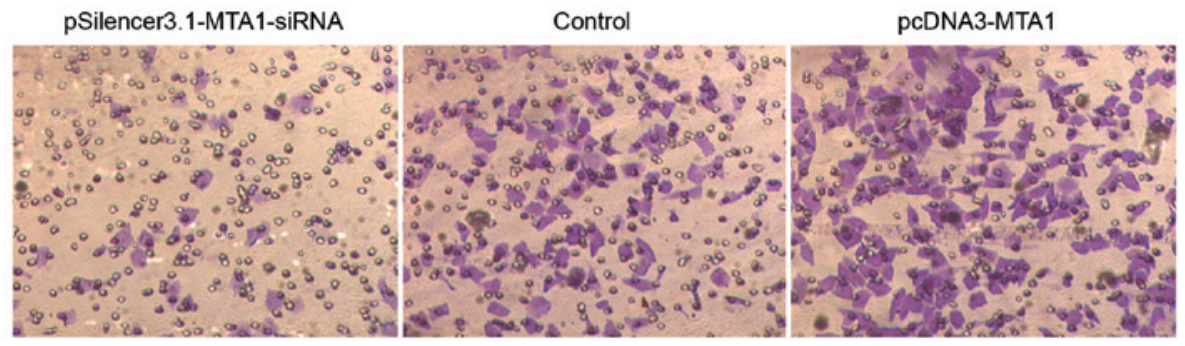

Figure 5. Invasion assay of HEP-2 cells after MTA1 overexpression and RNAi. The model used in this experiment was the same as that used in the migration assay. The difference is that the membrane used in this experiment was coated with extracellular matrix Matrigel $(250 \mu \mathrm{g} / \mathrm{ml})$. Compared with the control, the number of cells that invaded through the membrane in the pcDNA3-MTAl transfection group was markedly higher, while that in the MTAl-siRNA transfection group was lower $(\mathrm{P}<0.05)$. MTAl, metastasis-associated gene 1.

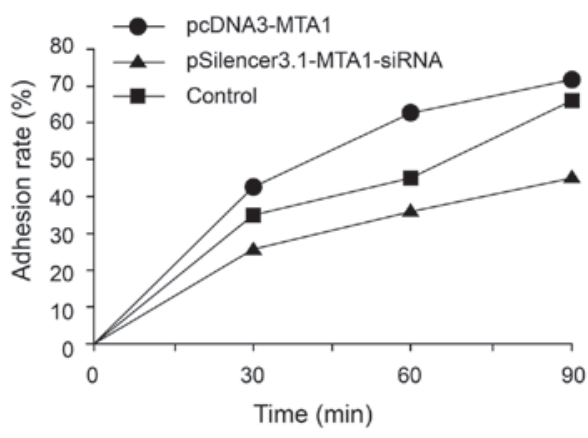

Figure 6. Adhesion assay of HEP-2 cells after MTA1 expression and RNAi. Variously treated cells were seeded into Matrigel-coated 96-well plates. The plates were washed evenly for the indicated times. The attached cells were determined to reflect their adhesion ability. Compared with the control, pcDNA3-MTA1 transfection promoted the adhesion of cells, while MTA1-siRNA transfection suppressed the adhesion of cells (both $\mathrm{P}<0.05$, compared with the control). MTA1, metastasis-associated gene 1.

tasis in vivo. We evaluated the effects of the MTAl gene on the adhesion ability of cancer cells. The results showed that, at the early stage of adhesion, pcDNA3-MTAl promoted the adhesion of HEP-2 cells to the Matrigel matrix, while silencing of MTA1 by RNAi inhibited the adhesion process. The adhesion rates of HEP-2 cells transfected with pcDNA3-MTAl, control-siRNA and $M T A 1$-siRNA at 30 min post-cell seeding were $41.8 \pm 7.16$, $35.6 \pm 6.08$ and $26.6 \pm 2.97 \%(\mathrm{P}<0.05$, MTAl-siRNA vs. control and pcDNA3-MTA1 groups), respectively; $63 \pm 10.44$, $46 \pm 8.34$ and $38.6 \pm 7.86 \%(\mathrm{P}<0.05, M T A 1$-siRNA vs. control and pcDNA3-MTAl groups) at 60 min post-cell seeding,

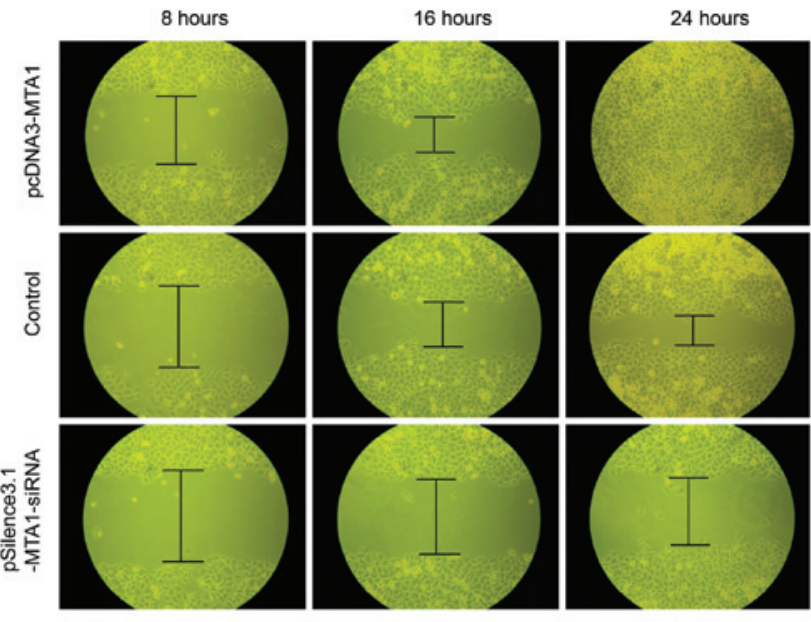

Figure 7. MTAl overexpression and RNAi changed the wound healing ability of the HEP-2 cell line. The variously treated cells were seeded into $35 \mathrm{~mm}$ dishes at the same density. The wound line was drawn in the cell layer with a sterile tip. The wound healing of cells differs corresponding to pcDNA3-MTAl or MTAl-siRNA transfection. At the designated time points, the healing of MTAl-siRNA transfected cells was significantly poorer. MTA1, metastasis-associated gene 1 .

respectively; and $71.2 \pm 6.83,63.6 \pm 7.56$ and $45 \pm 6.08 \%(\mathrm{P}<0.05$, $M T A 1$-siRNA vs. control and pcDNA3-MTAl groups) at $90 \mathrm{~min}$ post-cell seeding, respectively (Fig. 6). These results indicate that MTA1 may exert its effects on metastasis by regulating the adhesion molecules on the cell surface. 
Wound healing assay. For the wound healing assay, equal numbers of transfected HEP-2 cells were reseeded into 35-mm-diameter culture wells. The wound healing ability of cells reflects their movement on the surface to which they are anchored for growth. At 8, 16 and $24 \mathrm{~h}$ after wounding, the healing ability of MTAl-siRNA-transfected cells was significantly poorer than that of the pcDNA3-MTA1- and control-siRNA-transfected cells (Fig. 7).

\section{Discussion}

Cancer metastasis is the most common factor that causes cancer patient mortality and is a complex process involving a wide range of biological behaviors. It is urgent that the mechanisms underlying cancer metastasis be explored. Carcinogenesis involves several metastasis-associated molecules, many of which are altered during the process. Recent studies have revealed that $M T A 1$ is important in regulating cancer behaviors. MTAl expression has been associated with cancer malignancy in various cancer types, and has been found to increase the metastatic and invasive potential of carcinoma cells (12,31-33). LSCC is a type of cancer with a high potential for metastasis and invasion. To investigate whether MTAl is responsible, at least partially, for the metastatic potential of LSCC, MTAI gene function in the LSCC HEP-2 cell line was biologically studied using gene expression and RNAi techniques.

To confirm the correlation between MTAl and cancerous potential in LSCC cells, the MTAl level in HEP-2 and HaCaT cells was detected. It was observed that MTAl was expressed at relatively low levels in normal human keratinocyte $\mathrm{HaCaT}$ cell lines, while its expression was upregulated in HEP-2 cell lines. This result provided evidence supporting the function of MTAl in the development of human LSCC.

For further confirmation, gene transfection and RNA interference were performed to study MTAl functions in LSCC. RT-PCR and western blot analysis showed that the expression of MTAl was either suppressed or increased at the mRNA and protein level after pcDNA3-MTA1 and pSilencer3.1-MTA1-siRNA transfection. To confirm the association between MTAl expression and the metastatic potential of cancer cells, migration, invasion, adhesion and wound healing assays were performed after manipulating MTAl expression. The results showed that overexpression of MTAI promoted the metastasis potential of HEP-2 cells, while MTAI silencing by RNAi reversed the malignant phenotypes. The in vivo metastasis ability of HEP-2 was inhibited by MTAI silencing. In the cellular biological studies, a causal correlation between MTAl expression and the in vitro migration and invasion ability of LSCC cancer cells was identified.

Silencing of MTAl also impairs the angiogenesis of prostate cancer, partially eliminating the circumstance of cancer growth (34). These studies support the idea that MTAl may be a potential target for cancer therapy. In the current study, silencing of MTAl reversed the cancerous behaviors of LSCC, extending the therapeutic value of MTA1 in cancer treatment. MTA1-silencing was observed to result in a prominent loss of function in cancer cells, while overexpression of MTAl only increased cancerous behaviors to a certain extent. This may indicate that MTAl is critical in the life activity of cancer cells.
Molecular pathways were not the focus of the current study. Therefore, our next aim is to identify the mechanisms of MTA1 responsible for the change in biological phenotypes and in the structure-function relationship of MTA1.

In brief, the results of the present study demonstrate that the expression of MTA 1 promotes the migration and invasion ability of HEP-2 cells, indicating its importance in the progression of LSCC. Suppressing HDAC activity is currently the target of chemotherapy (35-37). MTA1, as an HDAC component of NURD complexes, may be a potential powerful target for LSCC biotherapy or chemotherapy.

\section{Acknowledgements}

This study was supported by the National Natural Science Foundation of China (81071773) and the Major State Basic Research Development Program (2009CB521807). The authors are greatly appreciative of their support.

\section{References}

1. Cattaruzza MS, Maisonneuve P and Boyle P: Epidemiology of laryngeal cancer. Eur J Cancer B Oral Oncol 32B: 293-305, 1996.

2. Forastiere A, Koch W, Trotti A and Sidransky D: Head and neck cancer. N Engl J Med 345: 1890-1900, 2001.

3. Greenlee RT, Hill-Harmon MB, Murray T and Thun M: Cancer statistics. CA Cancer J Clin 51: 15-36, 2001.

4. Song IH: Cancer metastasis and metastasis suppressors. Korean J Gastroenterol 43: 1-7, 2004.

5. Stracke ML and Liotta LA: Multi-step cascade of tumor cell metastasis. In Vivo 6: 309-316, 1992.

6. Toh Y, Pencil SD and Nicolson GL: A novel candidate metastasis-associated gene, mta1, differentially expressed in highly metastatic mammary adenocarcinoma cell lines. cDNA cloning, expression, and protein analyses. J Biol Chem 269: 22958-22963, 1994.

7. Xue Y, Wong J, Moreno GT, Young MK, Côté J and Wang W: NURD, a novel complex with both ATP-dependent chromatin-remodeling and histone deacetylase activities. Mol Cell 2: 851-861, 1998.

8. Gururaj AE, Singh RR, Rayala SK, Holm C, den Hollander $\mathrm{P}$, Zhang H, Balasenthil S, Talukder AH, Landberg G and Kumar R: MTA1, a transcriptional activator of breast cancer amplified sequence 3. Proc Natl Acad Sci USA 103: 6670-6675, 2006.

9. Qian H, Lu N, Xue L, Liang X, Zhang X, Fu M, Xie Y, Zhan Q, Liu Z and Lin C: Reduced MTA1 expression by RNAi inhibits in vitro invasion and migration of esophageal squamous cell carcinoma cell line. Clin Exp Metastasis 22: 653-662, 2005.

10. Qian H, Yu J, Li Y, Wang H, Song C, Zhang X, Liang X, Fu M and Lin C: RNA interference of metastasis-associated gene 1 inhibits metastasis of B16F10 melanoma cells in a C57BL/6 mouse model. Biol Cell 99: 573-581, 2007.

11. Sasaki H, Yukiue H, Kobayashi Y, Nakashima Y, Kaji M, Fukai I, Kiriyama M, Yamakawa Y and Fujii Y: Expression of the MTA1 mRNA in thymoma patients. Cancer Lett 174: 159-163, 2001.

12. Sasaki H, Moriyama S, Nakashima Y, Kobayashi Y, Yukiue H, Kaji M, Fukai I, Kiriyama M, Yamakawa Y and Fujii Y: Expression of the MTA1 mRNA in advanced lung cancer. Lung Cancer 35: 149-154, 2002.

13. Zhang H, Stephens LC and Kumar R: Metastasis tumor antigen family proteins during breast cancer progression and metastasis in a reliable mouse model for human breast cancer. Clin Cancer Res 12: 1479-1486, 2006.

14. Bagheri-Yarmand R, Talukder AH, Wang RA, Vadlamudi RK and Kumar R: Metastasis-associated protein 1 deregulation causes inappropriate mammary gland development and tumorigenesis. Development 131: 3469-3479, 2004.

15. Miyatani T, Kurita N, Mikami C, Kashihara H, Higashijima J, Yoshikawa K, Nishioka M, Sato H, Iwata T and Shimada M: Malignant potential of Barrett's esophagus: special reference to HDAC-1 and MTA-1 expression. Hepatogastroenterology 58: 472-476, 2011. 
16. Park JO, Jung CK, Sun DI, Joo YH and Kim MS: Relationships between metastasis-associated protein (MTA) 1 and lymphatic metastasis in tonsil cancer. Eur Arch Otorhinolaryngol 268: 1329-1334, 2011

17. Zhu X, Guo Y, Li X, Ding Y and Chen L: Metastasis-associated protein 1 nuclear expression is associated with tumor progression and clinical outcome in patients with non-small cell lung cancer. J Thorac Oncol 5: 1159-1166, 2010.

18. Mishra SK, Mazumdar A, Vadlamudi RK, Li F, Wang RA Yu W, Jordan VC, Santen RJ and Kumar R: MICoA, a novel metastasis-associated protein 1 (MTA1) interacting protein coactivator, regulates estrogen receptor-alpha transactivation functions. J Biol Chem 278: 19209-19219, 2003.

19. Yoo YG, Kong G and Lee MO: Metastasis-associated protein 1 enhances stability of hypoxia-inducible factor-1alpha protein by recruiting histone deacetylase 1. EMBO J 25: 1231-1241, 2006.

20. Li SH, Tian H, Yue WM, Li L, Li WJ, Chen ZT, Hu WS, Zhu YC and Qi L: Overexpression of metastasis-associated protein 1 is significantly correlated with tumor angiogenesis and poor survival in patients with early-stage non-small cell lung cancer. Ann Surg Oncol 18: 2048-2056, 2011.

21. Ghanta KS, Li DQ, Eswaran J and Kumar R: Gene profiling of MTA1 identifies novel gene targets and functions. PLoS One 6: e17135, 2011

22. Xu L, Mao XY, Fan CF and Zheng HC: MTA1 expression correlates significantly with cigarette smoke in non-small cell lung cancer. Virchows Arch 459: 415-422, 2011.

23. Cui FL, Gong DD, Zhou YJ, Zhu L and Fan Y: Regulatory effect of MTA1 on the anoikis of human prostate cancer cells. Zhonghua Nan Ke Xue 17: 427-430, 2011 (In Chinese).

24. Mazumdar A,WangRA,MishraSK,AdamL,Bagheri-YarmandR, Mandal M, Vadlamudi RK and Kumar R: Transcriptional repression of oestrogen receptor by metastasis-associated protein 1 corepressor. Nat Cell Biol 3: 30-37, 2001

25. Kumar R, Wang RA, Mazumdar A, Talukder AH, Mandal M, Yang Z, Bagheri-Yarmand R, Sahin A, Hortobagyi G, Adam L et al: A naturally occurring MTA1 variant sequesters oestrogen receptor-alpha in the cytoplasm. Nature 418: 654-657, 2002.

26. Li DQ, Pakala SB, Reddy SD, Ohshiro K, Peng SH, Lian Y, Fu SW and Kumar R: Revelation of p53-independent function of MTA1 in DNA damage response via modulation of the p21 WAF1-proliferating cell nuclear antigen pathway. J Biol Chem 285: 10044-10052, 2010.

27. Li DQ, Ohshiro K, Khan MN and Kumar R: Requirement of MTA1 in ATR-mediated DNA damage checkpoint function. J Biol Chem 285: 19802-19812, 2010.
28. Deng Y, Zhou D and Zeng L: Expression and significance of MTA1 and RECK gene in nasopharyngeal carcinoma. Lin Chung Er Bi Yan Hou Tou Jing Wai Ke Za Zhi 25: 534-538, 2011 (In Chinese)

29. Jiang Q, Zhang $H$ and Zhang P: ShRNA-mediated gene silencing of MTA1 influenced on protein expression of ER alpha, MMP-9, CyclinD1 and invasiveness, proliferation in breast cancercell lines MDA-MB-231 and MCF-7 in vitro. J Exp Clin Cancer Res 30: 60, 2011.

30. Rao Y, Wang H, Fan L and Chen G: Silencing MTA1 by RNAi reverses adhesion, migration and invasiveness of cervical cancer cells (SiHa) via altered expression of p53, and E-cadherin/ $\beta$-catenin complex. J Huazhong Univ Sci Technolog Med Sci 31: $1-9,2011$

31. Hofer MD, Kuefer R, Varambally S, Li H, Ma J, Shapiro GI, Gschwend JE, Hautmann RE, Sanda MG, Giehl K, et al: The role of metastasis-associated protein 1 in prostate cancer progression. Cancer Res 64: 825-829, 2004.

32. Toh Y, Ohga T, Endo K, Adachi E, Kusumoto H, Haraguchi M, Okamura T and Nicolson GL: Expression of the metastasis-associated MTA1 protein and its relationship to deacetylation of the histone $\mathrm{H} 4$ in esophageal squamous cell carcinomas. Int J Cancer 110: 362-367, 2004.

33. Kumar R, Wang RA and Bagheri-Yarmand R: Emerging roles of MTA family members in human cancers. Semin Oncol 30 (5 Suppl 16): 30-37, 2003.

34. Kai L, Wang J, Ivanovic M, Chung YT, Laskin WB, Schulze-Hoepfner F, Mirochnik Y, Satcher RL Jr and Levenson AS: Targeting prostate cancer angiogenesis through metastasis-associated protein 1 (MTA1). Prostate 71: 268-280, 2011.

35. Denlinger CE, Keller MD, Mayo MW, Broad RM and Jones DR: Combined proteasome and histone deacetylase inhibition in non-small cell lung cancer. J Thorac Cardiovasc Surg 127: 1078-1086, 2004

36. Warrell RP Jr, He LZ, Richon V, Calleja E and Pandolfi PP: Therapeutic targeting of transcription in acute promyelocytic leukemia by use of an inhibitor of histone deacetylase. J Natl Cancer Inst 90: 1621-1625, 1998.

37. Phillips T, Collins T and Davies J: American Association for Cancer Research - 96th Annual Meeting. Targeting the cell cycle and HDAC inhibitors. IDrugs 8: 450-453, 2005. 